\title{
Evaluation of Fertilizing Ability using Frozen Thawed Sperm in the Longtooth Grouper, Epinephelus bruneus
}

\author{
Seong-Rip $\mathrm{Oh}^{1}$, Chi-Hoon Lee ${ }^{2}$, Hyeong-Cheol Kang ${ }^{2}$, Young-Bo Song ${ }^{2}$, \\ Hyung-Bae $\mathrm{Kim}^{3}$ and ${ }^{\dagger}$ Young-Don Lee ${ }^{2}$ \\ ${ }^{1}$ Fisheries Resources Research Institute, Jeju Special Self-Governing Province, Jeju 697-914, Republic of Korea \\ ${ }^{2}$ Marine Science Institute, Jeju National University, Jeju 690-968, Republic of Korea \\ ${ }^{3}$ Dept. of Marine Life Science \& Aquaculture, Gangwon Provincial College, Gangwon 210-804, Republic of Korea
}

\begin{abstract}
This study examines the effects on fertilization rate (FR), hatching rate (HR), and normal individual rate after artificial fertilization using frozen thawed sperm according to the cryoprotectant (DMSO) concentration and the period of cryopreserved sperm of longtooth grouper, Epinephelus bruneus. Performing artificial fertilization using frozen-thawed sperm, after freezing the sperm at different DMSO concentration of 5.0\%, 7.5\%, 10.0\% respectively, FR were (DMSO 5.0\%: 99.5 $\pm 0.8 \%$, DMSO 7.5\%: 99.5 $\pm 0.7 \%$, and DMSO 10.0\%: 99.6 $\pm 0.6 \%$ ). The results are not significantly different from

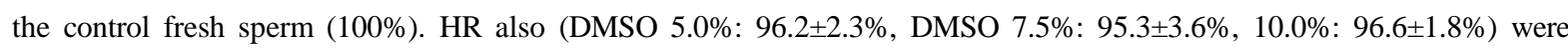
not significantly different in each group. The normal individual rate after hatching using with control fresh sperm $(98.4 \% \pm 0.5)$ and DMSO concentration level of 5.0\% (97.8 $\pm 0.1 \%)$ were not significantly different. However, with $7.5 \%$ (97.2 $\pm 0.6 \%)$ and $10.0 \%$ DMSO concentrations $(95.9 \pm 0.2 \%)$ are lower than the normal individual rate after hatching observed in the control and 5.0\% DMSO. Performing artificial fertilization using frozen-thawed sperm at different frozen period (2 days, 2 years, and 3 years), 10\% DMSO FR and HR of 3 years (FR; 66.8 $\pm 1.8 \%$, HR: 82.0 $\pm 12.9 \%$ ) and 2 years (FR; 78.5 $\pm 14.8 \%$, HR: 79.3 $\pm 0.6 \%$ ) cryopreserved sperm were lower than control (FR; 100\%, HR: 91.1 $\pm 3.6 \%$ ) and 2 days cryopreserved sperm (FR; 99.6 $\pm 0.6 \%$, HR: 96.6 $\pm 1.8 \%$ ). These results suggest suitable DMSO concentration ranges of cryopreservation sperm for E. bruneus is 5 to $10 \%$ and with 2 to 3 years cryopreservation period, cryopreservation sperm can be useful for seed production.
\end{abstract}

Key words : Longtooth grouper, Sperm cryopreservation, Fertilizing ability, DMSO

\section{INTRODUCTION}

Epinephelinae are known to be protogynous hermaphrodites in that they are all born female, and at some point in their lifespan some change sex to male. The grouper's natural sex reversal has been found in the greasy grouper E. tauvina (Chao \& Lim, 1991) showing it took seven years to have a natural sex reversal after hatching. Another study on the goldblotch grouper E. coatae (Glamuzina et al., 2000) showed $11 \mathrm{~kg}$ body weight fish naturally reverse sex. As for the redspotted grouper $E$. akaara (Hamamoto et al., 1986), the fish longer than 25 $\mathrm{cm}$ total length and heavier than $500 \mathrm{~g}$ body weight, had an increased ratio of males. Sex reversal in groupers makes it difficult to secure male fish in wild and seed production. Thus, sex reversal hormone treatment is being

\footnotetext{
Manuscript received 21 June 2013, Received in revised form 10 August 2013, Accepted 13 November 2013

${ }^{\dagger}$ Corresponding Author : Young-Don Lee, Marine Science Institute, Jeju National University, 19-5, Hamdeok 5(O)-gil, Jocheon, Jeju Special Self-Governing Province, Jeju 695-965, Republic of Korea. Tel./Fax : +82-64-782-8281, E-mail : leemri@jejunu.ac.kr

This is an Open Access article distributed under the terms of the Creative Commons Attribution Non-Commercial License(http://creativecommons. org/licenses/by-nc/3.0) which permits unrestricted non-commercial use, distribution, and reproduction in any medium, provided the original work is properly cited.
} 
used to produce functional males by injecting hormones into young female grouper. Previous experiments attempted masculization in groupers through hormonal manipulation. In the greasy grouper E. tauvina (Chen et al., 1977; Chao \& Chow, 1990), sevenband grouper E. septemfasciatus (Tsuchihashi et al., 2003; Song, 2004), and redspotted grouper E. akaara (Hwang et al., 1998), longtooth grouper E. bruneus (Oh et al., 2013), functional males were obtained when endogenous androgen or $17 \alpha$-methyltestosterone (MT) was administered. In the honeycomb grouper E. merra (Alam et al., 2006), an aromatize inhibitor, or an endogenous hormone, was used to induce masculinization.

Sperm storage, or sperm cryopreservation, is being used to preserve sperm cells to account for difficulty in securing male fish, inconsistent sexual maturation age and size, and gender imbalance that make it difficult to get sperm at the optimal timing for seed production. Sperm cryopreservation has the benefit in that sperm from healthy fish can be selected to prevent disease. Also, it is economically more efficient than using larvae for breeding (Lubzens et al., 1997). It has been used in many species such as: the tilapia Sarotherodon mossambicus (Harvery, 1983), the common carp Cyprinus carpio (Kurokura et al., 1984), the rainbow trout Salmo gairdneri (Baynes \& Scott, 1987) in freshwater fish and the alabar grouper Epinephelus malabaricus (Chao et al., 1992), the tiger pufferfish Takifugu rubripes (Chang et al., 1998), the black sea bream Acanthopagrus schlegeli (Lim et al., 1997), and the flatfish Paralichthys olivaceus (Zhang et al., 2003) in seawater fish. This study aims was to evaluate of fertilizing ability using frozen thawed sperm to investigate the fertilization rate and the hatching rate depending on the cryoprotectant concentrations for cryopreservation and the cryopreserved period to find optimal sperm levels and better preservation techniques for artificial seed production of longtoogh groupers.

\section{MATERIALS AND METHODS}

\section{Experimental group}

The semen for the experiments was collected from a wild caught longtooth grouper (total length $76 \mathrm{~cm}$, body weight $6.4 \mathrm{~kg}$ ) that had been reared in an inner concrete tank $(5 \times 5 \times 3 \mathrm{~m})$, with the water capacity of $62 \mathrm{~m}^{3}$ at the Ocean and Fisheries Research Institute in Jeju Province in 2005.

For sperm cryopreservation in longtooth groupers, Ringer's solution was used as a diluent (Table 1) and dimethyl sulfoxide (DMSO, Sigma Co., Ltd. USA) was used as a cryoprotectant. The equilibration time between a semen and the diluent was regulated within 1 minute, and a 0.5 $\mathrm{ml}$ semen straw was used for freezing.

2. Fertilizing ability of cryopreserved sperm depending on DMSO concentrations

To determine the optimal proportion of diluents and cryoprotectants that minimizes freezing injuries during the procedure to cryopreserve the sperm, diluents and cryoprotectants were mixed in different proportions (Table 2). We placed $0.5 \mathrm{ml}$ of the diluted semen with cryo-

Table 1. Composition of diluents used sperm cryopreservation of longtooth grouper, $E$. bruneus

\begin{tabular}{lc}
\hline \multicolumn{1}{c}{ Constituent } & Formula weight \\
\hline $\mathrm{NaCl}$ & $10.00 \mathrm{~g}$ \\
$\mathrm{KCl}$ & $0.22 \mathrm{~g}$ \\
$\mathrm{CaCl}_{2}$ & $0.25 \mathrm{~g}$ \\
$\mathrm{MgSO}_{4} \quad 7 \mathrm{H}_{2} \mathrm{O}$ & $0.74 \mathrm{~g}$ \\
$\mathrm{HEPES}\left(\mathrm{C}_{8} \mathrm{H}_{18} \mathrm{~N}_{2} \mathrm{O}_{4} \mathrm{~S}\right)$ & $1.19 \mathrm{~g}$ \\
Glucose & $0.9 \mathrm{~g}$ \\
Streptomycin & $0.1 \mathrm{~g}$ \\
Penicillin G & $100,000 \mathrm{unit}$ \\
Distilled water & $1,000 \mathrm{ml}$ \\
$\mathrm{pH}$ & 7.4 \\
\hline
\end{tabular}

Table 2. Quantities of diluents, DMSO, and fresh semen in three different DMSO concentration trials

\begin{tabular}{cccc}
\hline \hline $\begin{array}{c}\text { Experimental } \\
\text { group }\end{array}$ & $\begin{array}{c}\text { Diluent } \\
(\mathrm{ml})\end{array}$ & $\begin{array}{c}\text { DMSO }^{1)} \\
(\mathrm{ml})\end{array}$ & $\begin{array}{c}\text { Fresh semen } \\
(\mathrm{ml})\end{array}$ \\
\hline 5.0\% DMSO & 7.50 & 0.50 & 2.00 \\
$7.5 \%$ DMSO & 7.25 & 0.75 & 2.00 \\
10\% DMSO & 7.00 & 1.00 & 2.00 \\
\hline
\end{tabular}

1) DMSO: dimethyl sulfoxide. 
protectants into the straw and then sealed the straw. The sealed straw was stored in a liquid nitrogen tank $\left(-196^{\circ} \mathrm{C}\right)$ after being frozen for 15 minutes at liquid nitrogen vapor $\left(-96^{\circ} \mathrm{C}\right)$. After 48 hours, the cryopreserved sperm were thawed in filtered seawater $\left(22 \pm 1.0^{\circ} \mathrm{C}\right)$ and then used for the experiments. For the fertilization rates analysis depending on the DMSO concentrations, we mixed $20 \mathrm{~g}$ of the ovulated eggs administrating human chorionic gonasotropin (HCG, Calbiochem Co., Ltd. USA) and $0.1 \mathrm{ml}$ of cryopreserved semen respectively and then added filtered seawater gradually to induce artificial fertilization. For the control group, cryoprotected fresh semen and diluents were diluted at the ratio of 1 to 49.4 hours after the artificial fertilization, aliquots of the buoyant eggs were randomly selected and normally developing eggs were counted in a profile projector (PJ-H3000F, Japan) for the fertilization rates. For the hatching rates analysis depending on the DMSO concentrations, 80 to 100 fertilized buoyant eggs were randomly selected, counted under the profile projectors, placed in a $500 \mathrm{ml}$ beaker, and then hatched. The hatching rates were calculated for the non fertilized eggs for the past 60 hours after the artificial fertilization whilst the water temperature was maintained at $21.0 \pm 0.5^{\circ} \mathrm{C}$. The ratio of normally developed fish out of the total hatching larvae, excluding the ratio of dead fish right after the hatching and abnormally developed ones like those with spinal curvature, was calculated and every observation was done thrice repetitively.

\section{Fertilizing ability of cryopreserved sperm depending} on the preserved period

The fertilization rates and hatching rates were analyzed to examine the fertilizing ability of the cryopreserved sperm according to the period of cryopreservation. We diluted DMSO and diluents at the ratio of 1 to 7 , mixed DMSO and diluents with the ratio of 1 to 7 , and then diluted the mixed solution with semen 5 times (semen 1: mixed solution 4). We then injected $0.5 \mathrm{ml}$ of the diluted solution containing cryoprotectants into the straw and sealed the end of the straw. The sealed straw was stored in a liquid nitrogen tank after being frozen for 15 minutes at liquid nitrogen vapor. The fertilizing ability after being thawed was determined by fertilization rates and the hatching rates of the artificially fertilized embryos using thawed sperm after the cryopreservation 2 days, 2 years, and 3 years. The fertilization rates and hatching rates were analyzed in the same method as cryopreservation analysis depending on the DMSO concentrations.

\section{Statistical analysis}

The data was analyzed for statistical significance of means using the ANOVA-test and Duncan's multiple range test (Duncan, 1955) with SAS software.

\section{RESULTS}

\section{Fertilizing ability depending on the DMSO con-} centration

The fertilization rates at different DMSO concentration groups of $5.0 \%, 7.5 \%$, and $10.0 \%$, respectively, were $99.5 \pm 0.8 \%, 99.5 \pm 0.7 \%$ and $99.6 \pm 0.6 \%$ showing the exact same results from the fertilization rates of the control group ( $P>0.05$, Fig. $1 \mathrm{~A})$.

The hatching rates at different DMSO concentrations in control group were the lowest at $89.1 \pm 1.4 \%(P<0.05)$, and the hatching rates in the experimental groups of different DMSO concentrations of 5.0\%, 7.5\%, and $10.0 \%$ were $96.2 \pm 2.3 \%, 95.3 \pm 3.6 \%$, and $96.6 \pm 1.8 \%$ respectively $(P>0.05$, Fig. 1B).

The rates showing the normal development were $98.4 \pm 0.5 \%$ in the control group and $97.8 \pm 0.1 \%$ in the experimental group at the DMSO concentration of $5.0 \%$, showing no significant difference $(P>0.05)$. Though the normally developed fish rates in the experiment group at the DMSO concentrations of $7.5 \%$ and $10.0 \%$ were $97.2 \pm 0.6 \%, 95.9 \pm 0.2 \%$ showing lower rates than the control group $(P<0.05$, Fig. $1 \mathrm{C})$.

2. The fertilization rates of the cryopreserved sperm at different periods 

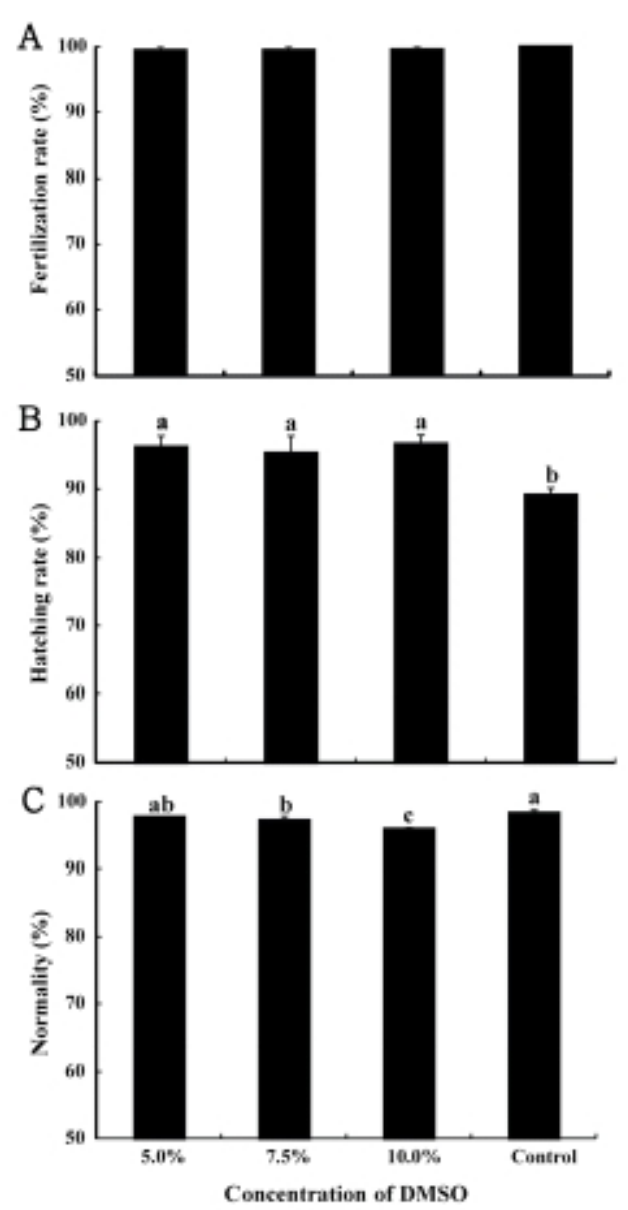

Fig. 1. Fertilizing ability of frozen-thawed semen froze with three DMSO concentrations levels. A, Fertilization rates; B, Hatching rates; C, Normality. Small letters indicate significant differences at $P<0.05$. Vertical bars denote standard errors of means.

The fertilization rates at the cryopreserved periods of 2 days, 2 years, and 3 years were $99.6 \pm 0.6 \%, 78.5 \pm 14.8 \%$, and $66.8 \pm 1.8 \%$, respectively, showing the highest rate in the 2 days group $(P<0.05)$. The control group, with fresh semen, showed exactly the same result as the 2 days experimental group ( $P>0.05$, Fig. $2 \mathrm{~A})$. The hatching rates in the experimental groups at different cryopreserved periods of 2 years and 3 years were $79.3 \pm 0.6 \%$ and $82.0 \pm$ $12.9 \%$ respectively showing no statistically significant difference $(P>0.05)$. The 2 days experimental groups and the control group also showed similar results showing 96.6 $\pm 1.8 \%$, 91.1 $\pm 3.6 \%$, respectively $(P>0.05)$. However, the control group and the 2 days sample group represented
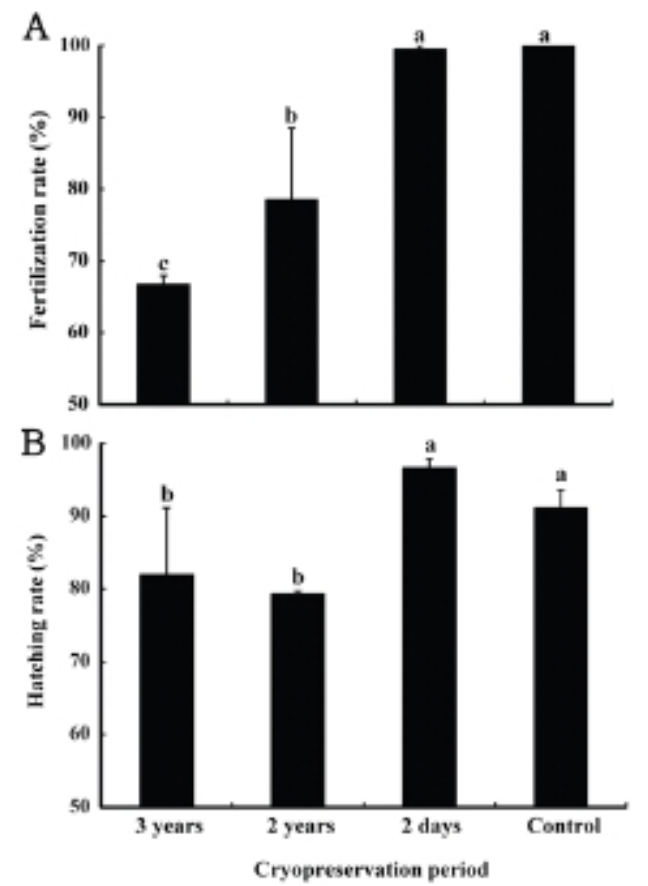

Fig. 2. Fertilizing ability of frozen-thawed semen by cryopreservation periods. A, Fertilization rate; B, Hatching rate. Small letters indicate significant differences at $P<0.05$. Vertical bars denote standard error of means.

higher rates than other sample groups ( $P<0.05$, Fig. 2B).

\section{DISCUSSION}

Semen cryopreservation is a successful procedure to preserve sperm of fish that have difficulties to secure male fish because they are protogynous hermaphrodite. For the issues that make it difficult to get sperm such as: being protogynous hermaphrodites, inconsistent sexual maturation age and size, and gender imbalance, the semen cryopreservation is a successful method to solve the issues. Various diluents and cryoprotectants have been used to cryopreserve the sperms (Bolla et al., 1987; Gwo et al., 1991; Babiak et al., 1995).

Osmotic concentration of the diluents, for the sperm cryopreservation, should be similar with the ones of the sperm, so the diluents can inhibit the sperm motility. Also the components are to be similar with the ion composition (Jamieson, 1991). The combined diluents of sodium chloride, glucose, and sucrose were used for the 
sperm cryopreservation of the Atlantic croaker Micropogonias undulates. Mounib's solution and marine fish Ringer's solution were effective for the sperm cryopreservation of the Atlantic halibut Hippoglossus hippoglossus (Bolla et al., 1987; Gwo et al., 1991). The black grouper E. malabaricus showed the highest sperm motility in the combination of $150 \mathrm{mM}$ of $\mathrm{NaCl}$ and Ringer's solution for marine fish (Gwo, 1993).

5\% glucose and Ringer's solution for marine fish were mixed as the diluents for the sperm cryopreservation of Epinephelinae fish, which represented no difference in the fertilization rates and hatching rates from the fresh semen group. This results in the osmotic concentration and $\mathrm{pH}$ in Ringer's solution, as $350 \mathrm{mOsm} / \mathrm{kg}$ and $\mathrm{pH}$ 7.39 , were similar with the ones in the plasma of sevenband grouper E. septemfasciatus plasma as $395 \mathrm{mOsm} / \mathrm{kg}, \mathrm{pH}$ 7.30 (Song, 2004).

Glycerol, DMSO, and methanol are the mainly used as cryoprotectants (Gwo \& Arnold, 1992; Zhang et al., 2003). DMSO generally gives successful results for most marine fish such as olive flounder Paralichthys olivaceus and turbot Scophthalmus maximus because of the fast penetration into spermatozoa, its interaction with the sperm membrane, and not affecting on sperm motility during the freezing or thawing (Dreanno et al., 1997; Zhang et al., 2003). For the black grouper E. malabaricus, it showed more sperm motility when $20.0 \%$ of DMSO was used than when glycerol or methanol was used (Gwo, 1993). As for the sperm cryopreservation of the sevenband grouper E. septemfasciatus, $5.0 \%$ of DMSO represented better fertilization ability than the group with a yolk buffer (Song, 2004).

As for the fertilization rates and hatching rates of frozen-thawed sperms in the longtooth grouper, it showed no significant difference based on DMSO concentrations (5.0\%, 7.5\%, and $10.0 \%$ ). The rates to have normally developed larvae, in the group of artificially fertilized eggs from the frozen-thawed semen, were from 97.8 to $95.9 \%$, which is lower than the control group with fresh semen, as it is $98.4 \%$. The abnormality occurs when artificially fertilized eggs from the thawed sperms had been genetically changed during the freezing and thawing processes and not developed normally (Julia et al., 2004; Miskolczi et al., 2005). The grass carp Ctenopharyngodon idellus had abnormality rates depending on the DMSO concentration, showing that the more concentrated cryoprotectans are used, the higher deformation rates. This assumes that there was a genetic change caused by cryopreservation (Dang et al., 2006).

The fertilizing ability in the 3 year frozen group had the fertilization rate of $66.8 \%$ and the hatching rate of $82.0 \%$, representing lower fertilization rates and hatching rates than the control group with fresh semen. Flatfish (Zhang et al., 2003) and grass carp (Dang et al., 2006) showed the fertilization rates of 40 to $50 \%$ when they were artificially fertilized with fresh semen but the hatching rates were $90 \%$. In addition, African clariid catfish (Oteme et al., 1996) had a $78.9 \%$ hatching rate from the 8 month cryopreserved sperm. However, this present study demonstrates that the two year cryopreserved sperm group and the three year cryopreserved sperm group has a higher fertilization rates as in $79.3 \%$ and $82.0 \%$, which indicates successful usage. Thus, it suggests that $10 \%$ or less of DMSO and Ringer's solution for marine fish are optimal diluents for the long term semen method. Also, the longer the cryopreservation period of sperm, fertilizing ability is decline and increase abnormality rate. It is more efficient to set an appropriate period for the cryopreservation to produce better quality eggs.

\section{REFERENCES}

Alam MA, Bhandari RK, Kobayashi Y, Soyano K, Nakamura M (2006) Induction of sex change within two full moons during breeding season and spawning in grouper. Aquaculture 255:532-535.

Babiak I, Glogowski J, Luczynski MJ, Kucharczyk D, Luczynski M (1995) Cryopreservation of the milt of the northern pike. J Fish Biol 46:819-828.

Baynes SM, Scott AP (1987) Cryopreservation of rainbow 
trout spermatozoa: the influence of sperm quality and extender composition on post-thaw fertility. Aquaculture 66:53-67.

Bolla S, Holmefjord I, Refstie T (1987) Cryogenic preservation of Atlantic halibut sperm. Aquaculture 65: 371-374.

Chang YJ, Chang YJ, Lim HK (1998) Physico-chemical preperties of milt and fine structure of cryopreserved spermatozoa in tiger puffer (Takifugu rubripes). J Korean Fish Soc 31:353-358. (in Korean)

Chao NH, Tasi HP, Liao IC (1992) Short and long term cryopreservation of sperm and sperm suspension of the grouper, Epinephelus malabaricus (blotch and Schneider). Asian Fish Sci 5:103-116.

Chao TM, Chow M (1990) Effects of methyltestosterone on gonadal development of the Epinephelus tauvina (Forskal). Singapore J Pri Ind 18:1-14.

Chao TM, Lim LC (1991) Recent development in the breeding of grouper (Epinephelus spp.) in Singapore. Singapore J Pri Ind 19:79-93.

Chen FY, Chow M, Chao TM, Lim R (1977) Artificial spawning and larval rearing of the grouper, Epinephelus tauvina (Forskal) in Singapore. Singapore J Pri Ind $5: 1-21$.

Dang TM, Pham MA, Pham AT, Lee KJ (2006) Effect of dimethyl-sulfoxide on sperm cryopreservation of grass carp (Ctenopharyngodon idellus). J Aquaculture 19:52-59.

Dreanno C, Suquet M, Quemener L, Cosson J, Fierville F, Normant Y, Billard R (1997) Cryopreservation of turbot spermatozoa. Theriogenology 48: 589-603.

Glamuzina B, Glavic N, Tutman P, Kozul V, Skaramuca B (2000) Notes on first attempt at artificial spawning and rearing of early stages with gold blotch grouper, Epinephelus coatae (Steindachner, 1875). Aquac Int 8:551-555.

Gwo JC (1993) Cryopreservation of black grouper (Epinephelus malabaricus) spermatozoa. Theriogenology 39:1331-1342.

Gwo JC, Arnold CR (1992) Cryopreservation of Atlantic croaker spermatozoa: Evaluation of morphological changes. J Exp Zool 264:444-453.

Gwo JC, Strawn K, Longnecker MT, Connie R (1991) Cryopreservation of Atlantic croaker spermatozoa. Aquaculture 94:355-375.

Hamamoto S, Yokogawa K, Tochino M (1986) Several problems on cultivating the parent fish of red spotted grouper, Epinephelus akaara (Temminck et Schlegel) and judging the qualities of the eggs obtained from them. Bull Kagawa Exp Stn 2:13-21.

Harvey B (1983) Cryopreservation of Sarotherodon mossambicus spermatozoa. Aquaculture 32:313-320.

Hwang SI, Lee YD, Song CB, Rho S (1998) Gonadal development and the effect of $17 \alpha$-methyltestosterone on sex inversion of the red spotted grouper, Epinephelus akaara. Aquaculture 11:173-182. (in Korean)

Jamieson BGM (1991) Fish evolution and systematics: Evidence from Spermatozoa. Cambridge University Press New York, pp 319.

Julia K, Eugency K, Tiantian Z, David MR, William VH (2004) Effect of DNA repair inhibitor (3-aminobenzamide) on genetic stability of loach (Misgurnus fossilis) embryos derived from cryopreserved sperm. Theriogenology 61:1661-1673.

Kurokura H, Hirano R, Tomita M, Iwahashi M (1984) Cryopreservation of carp sperm. Aquaculture 37:267273.

Lim HK, Kho KH, Change YJ (1997) Effect of dilutents on the short-term storage of sperm in black seabream, Acanthopagrus schlegeli. J Korean Fish Soc 30:211215. (in Korean)

Lubzens E, Daube N, Pekasky I, Magnus Y, Cohen A, Yusefovich F, Feigin F (1997) Carp (Cyprinus carpio) spermatozoa cryobanks-strategies in research and application. Aquaculture 155:13-30.

Miskolczi E, Mihalffy S, Varkonyi EP, Urbanyi B, Horvath A (2005) Examination of larval malformation in African catfish Clarias gariepinus following fertilization with cryopreserved sperm. Aquaculture 247:119-125.

Oh SR, Kang HC, Lee CH, Hur SW, Lee YD (2003) 
Sex reversal and masculinization according to growth in longtooth grouper Epinephelus bruneus. Dev Reprod 17:79-85.

Oteme JZ, Rodriguez JN, Kouassi CK, Hem S, Agnese JF (1996) Testicular structure, spermatogenesis and sperm cryopreservation in the African clariid catfish Heterobranchus longifilis (Valenciennes, 1840). Aquaculture Research 27:805-813.

Song YB (2004) Induction of sexual maturation and early development of the sevenband grouper, Epinephelus septemfasciatus. Ph. D. Thesis, Jeju National University. Jeju. Korea.

Tsuchihashi Y, Tanaka H, Kuromiya Y, Kashiwagi M, Yoshioka M (2003) Control of iduction of sex reversal in the sevenband grouper, Epinephelus septemfasciatus, Suisanzoshoku 51(2):189-196.

Zhang YZ, Zhang SC, Liu XZ, Xu YY, Wang CL, Sawant MS, Li J, Chen SL (2003) Cryopreservation of flounder, Paralichthys olivaceus sperm with a practical methodology. Theriogenology 60:989-996. 